\title{
OS GRANDES PROBLEMAS ECONOMICOS
}

\section{REGENERAÇÃO ECONOMICA}

Tem-se ultimamente falado, com insistencia, na regeneração economica do Brasil e particularmente na intensificação da producção. Acertado é o conselho de procurarmos augmentar nossa producção, e, neste sentido, a guerra fez que, na Europa, houvesse uma forte corrente de vulgarização da idéa de produzir mais, ameaçados os homens, hoje envolvidos no tremendo conflicto, de verem faltar-lhes alimentos. Não regatearei applausos aos que se empenharam nessa lucta em prol do enriquecimento da Patria pela intensificação do trabalho: desde o professor Gide, que, em prelecção inaugural, fazia sentir a seus discipulos ser este um dōs mais arduos problemas do momento, desde o nosso presidente, dr. Wencesláu Braz, que, em manifesto ao povo, convidava os brasileiros a cuidarem de augmentar seu esforço productivo, até ao mais obscuro propagandista que, nas aldeias, em França, prega cartazes, convidando os camponezes a plantarem trigo, affirmando-lhes que, dest'arte, se enriquecerão e, ao mesmo tempo, servirão á Patria, todos são dignos de louvores. Alguma cousa mais, porém, ha a fazer na intensificação do trabalho, como passo a mostrar, e é evitarmos que nossos concidadãos percam, por nossa culpa, seu tempo, e buscarmos a solução de outros problemas economicos ligados á distribuição, á circulação e ao consumo da riqueza. Desde já, porém, direi que não julgo tão máu quanto alguns de nosșos concidadãos dizem, quiçá levados por um excesso de pa- 
triotismo, o nosso estado economico. Muito nos cumpre fazer pela nossa regeneração economica, mas não nos devemos deixar tomar de panico, porque as forças de nossa querida Patria são extraordinarias, justificando, de algum modo, o dicto de um norte-americano, nosso hospede, ha pouco, isto é, que, mesmo sem governo, o Brasil, pelas suas proprias forças naturaes, enriquecerá facilmente, o que equivale a dizer que a doutrina do "laisser faire" é excellente em nosso paiz. Não sou tão optimista que não creia necessaria a acção governamental. Ao contrario, penso que ella é indispensavel, para nosso enriquecimento. Quando o não fosse, ao menos concorreria salutarmente com as forças naturaes, salvo o caso, que não desejo presumir, de uma direcção inepta e damnosa para o nosso desenvolvimento.

2) Sem duvida, nossa vida economica tem se resentido de falta de uma linha firme de acção, por parte de nossos governos. Não é isso devido a defeito dos dirigentes, mas ao regimen democratico, que, a par de grandes vantagens, tem a da instabilidade dos individuos que occupam os cargos sociaes, donde a impossibilidade de se manter uma só politica economica. Refiro-me tanto á nossa antiga monarchia, de caracter liberal, como tambem ao regimen republicano. Em nossa Politica, temos procurado manter a unidade de direcção unicamente nas relações internacionaes, preoccupação já do Imperio, já da Republica. Em plano de regeneração economica, tivemos muitos, todos frustados pela circumstancia da instabilidade governamental. Basta referir os de Belisario e de Murtinho. Quanto a este defeito do regimen democratico, entendo que não é de difficil correcção, si á direcção dos negocios economicos procurar o Brasil dar a continuidade que, até certo ponto, conseguiu imprimir na das relações internacionaes. Além dessa difficuldade na direcção economica de nossa Patria por causa da mudança continua de rota, pela frequente substituição dos ministros da Fazenda, 
ha uma difficuldade peculiar a nosso paiz. Pôl-a-ei em destaque, não só para justificar o Brasil da inferioridade em que se acha em relação aos Estados Unidos da America do Norte, mas tambem para mostrar com quanta difficuldade deveremos luctar para o nosso progresso economico, sem embargo da riqueza natural com que foi aquinhoada nossa Patria.

3) A America do Norte, em razão do clima temperado, poude, sem hesitações, adoptar todos os processos technicos tradicionaes na velha Europa. Sua organização industrial como é claro, foi recebida prompta do velho continente. Cousa muito diversa se passou em nosso paiz. O clima quente exige outras culturas, nas quaes teremos de fazer continuas experiencias, e é inutil insistir emquanto são ellas dispendiosas, tendo sido a esta circumstancia que se referiu o prof. Gide, quando, em carta que me dirigiu, affirmou muito haver a fazer em meu paiz para um joven economista. Darei exemplos. Discutem os mestres em pecuaria sobre a raça bovina que mais convém ao nosso paiz. Ha partidarios do zebú. Supponhamos que, introduzido em larga escala, como está sendo o zebú, venha a tornar-se o gado geral, e é isto de esperar, pois os resultados immediatos colhidos pelos criadores são evidentemente maiores com essa raça do que com qualquer outra. Figuremos, porém, a hypothese de se averiguar, dentro de alguns annos, em poucas gerações, que fornece insignificante quantidade de leite, que tem carne pessima, rejeitada pelo consumidor, e condemnada pelos medicos por ser rica em toxinas. Dado isto, teremos de mudar a raça, e não preciso encarecer as difficuldades dessa medida. Lembremo-nos de que não podemos comparar o que se sabe da cultura da vinha, do trigo, da aveia, com o conhecido sobre a da canna e do cacau. Exemplo frisante, eloquentissimo, temos nas culturas da mangabeira e da maniçoba. Quem se lançar nessas culturas, está no imprevisto, quasi nas condições dos que se sacri- 
ficaram para descobrir a direcção dós balóes, perdendo fortunas na empresa. Si pois temos uma grande fertilidade do solo e riquezas mineraes, em compensação, temos a difficuldade de dever formar uma nova technica propria para o nosso clima, quer quanto á agricultura, quer quanto á pecuaria.

4) Tornando á affirmação do americano, e fallando em geral, tenho a observar que, de facto, o desenvolvimento economico, até certo ponto, não depende da influencia governamental, e quando a riqueza particular se accentua, facilita a solução dos problemas financeiros, pois é assás claro que, para um povo rico, é muito facil pagar os impostos, e sua prosperidade dispensa o governo de pensar em emprestimos publicos. E' comtudo elementar e innegavel que as boas finanças facilitam o augmento da riqueza publica e da dos particulares.

$\mathrm{Da}$ influencia que a direcção financeira exerce sobre a producção temos prova cabal na conhecidissima circumstancia do desenvolvimento das empresas, quando ha abundancia de moeda no mercado. Si o governo, imprudentemente, lança com excesso papel moeda no mercado, começam logo a apparecer empresas loucas, temerarias, conforme é reconhecido por todos os economistas. Ao contrario, como é bem de ver, si ha carencia de numerario, logo as empresas se tornam menos numerosas, ha um esmorecimento geral na producção. Um outro exemplo eloquente de quanto póde influir o governo na sorte do desenvolvimento economico de um paiz, temos nos impostos de importação. Si o nosso governo lançar sem prudencia impostos sobre os productos de um paiz extrangeiro, verá esse paiz, em represalia, tributando pesadamente os nossos productos: lancemos um imposto forte sobre os vinhos franceses, e veremos a França tributando pesadamente o nosso café. Não se torna preciso fazer sentir quaes serão as consequencias deste facto sobre a fortuna dos particulares. 
Passarei a ver como tem procedido nosso governo no momento gravissimo que atravessamos.

5) Começarei por dizer que tem elle feito o possivel, e que o povo nenhuma queixa póde ter daquelle a quem confiou os destinos da Patria, e que se acha na presidencia da Republica, nem mesmo dos deputados, que fizeram tudo quanto era humanamente possivel, o que não impede que diga eu que muita cousa ainda resta a fazer, aconselhada pela sciencia economica. Tenhamos presentes duas circumstancias das mais importantes para a defesa dos que se acham incumbidos de zelar os destinos da Patria. A primeira é que o governo do marechal Hermes, cuja probidade por ninguem, em boa fé, é posta em duvida, foi infeliz em despesas: póde ser considerado seu quatriennio um periodo de erros economicos e de prodigalidade. Foi com os cofres vasios, com as finanças desorganizadas que entrámos na crise determinada pela guerra. Para os homens de espirito recto, tendo em attenção reste facto, o actual governo, e quero me referir tanto ao presidente, como ao Congresso que acabou seu triennio, é digno de nosso respeito. A segunda circumstancia é a necessidade de preparar a defesa militar. Acertadamente têm dado nossos homens publicos muito maior attenção ao preparo da defesa pelas armas, do que aa desenvolvimento economico. Tem-se dito que o nervo da guerra é o ouro. A actual guerra demonstrou quanto é falso este proverbio. Guerra não se faz sempre com dollars ou com libras esterlinas, mas com bala. Não se póde negar que houve muitas guerras feitas a ouro, por soldados mercenarios. Momentos ha, porém, em que o ouro absolutamente nada adeanta para o resultado da lucta. O grande professor de Economia Politica em Lyão, René Gonnard, em uma lição de abertura de curso, que deveria ter sido lida ao deixar o antigo mestre a farda de soldado para tomar de novo a béca de doutor, mostrou que o materialismo historioo falliu, em consequencia da actual conflagraçāo, 
ficando bem accentuado e provado não ser unicamente or interesse pecuniario que move o homem, e, nas condições em que hoje se acham os povos europeus, torna-se inutil o dinheiro como sendo meio de lucta entre os povos. 0 desenvolvimento da riqueza de um paiz deve ser acompanhado do de sua força militar, aliás correrá o risco de, excitando a cobiça de outras nações, ver seu territorio invadido e seu solo conquistado pelo inimigo ambicioso.

Num excellente artigo do grande economista Daniel Bellet, que acabo de ler, na Revista de Economia Politica, vejo o desenvolvimento desta these, ao estudar o mestre o enriquecimento da Allemanha, assumpto que tanto tem preoccupado os sabios nestes ultimos tempos. E' hoje acquisição da sciencia que ds povos, do mesmo modo que os individuos, devem augmentar seus meios de defesa, á medida que enriquecem. Não posso dizer como têm procedido os governantes nos diversos Estados do Brasil, pois só conheço o que foi feito pela União e pelo Estado de S. Paulo. Quanto a estes dois, creio que seguiram bom rumo, pensando primeiro na defesa pelas armas, e collocando em segundo plano a regeneração economica, de que vou dizer algumas palavras. Antes, porém, de me occupar com ella, farei breves observações sobre as nossas relações mercantis internacionaes no grave momento em que nos achamos.

6) A escola mercantilista, que esteve em grande voga no seculo XVI, e cujas doutrinas se acham compendiadas em uma obra de Antonio Mont-Crétien, publicada em 1615, ligava grande importancia á chamada. "balança do commercio", e queria que os Estados possuissem a maior quantidade de ouro possivel, pois para ella este era a verdadeira riqueza. A escola dos physiocratas, no seculo XVIII, criticou e aniquilou o mercantilismo, ao menos na parte relativa á balança do commercio, substituida pela doutrina da "balança de contas". A opinião sobre o valor do ouro como representante de riqueza modificou-se tam- 
bem profundamente, sob a influencia do progresso da Sciencia Economica. Em artigo que publiquei no "Jornal do Commercio", do Rio de Janeiro, a 25 de dezembro do anno passado, mostrei o que se deve pensar sobre essa these do mercantilismo, defendida ainda por alguns economistas, não obstante a quéda da escola. Como se sabe, não é raro que uma escola desappareça, e que alguns de seus erros perdurem nas obras daquelles escriptores, mesmo que mais a atacaram. Fiz sentir nesse artigo, que o ouro vai perdendo gradativamente sua importancia, e que o prògresso da sciencia demonstrou que o seu papel hoje é unicamente o que tem qualquer meio de acquisição de productos, achando-se pois no mesmo nivel das demais formas ou modalidades da moeda, e até dos succedaneos da moeda. Sabemos todos quantos temos conhecimento do que seja a circulação fiduciaria, a pouca importancia dos metaes nas transacções sociaes hodiernas, mesmo nas internacionaes, pois estas, como diz Ricardo, tendem a tomar a fórma de troca ou permuta, e o numerario intervem nellas, segundo Gide, unicamente na proporção de $3 \%$ ou $4 \%$. Os leigos julgam que estaria nossa salvação em termos muitas minas de ouro, podermos rivalizar com o Transwaal, com a California, com a Bolivia, que tem a dita de possuir o Potosi. Este erro arraiga-se agora no espirito publico, ao ouvirem os poucos versados em Economia Politica que a Argentina está guardando suas reservas em ouro, e que o Brasil pensa prohibir a exportação do ouro desde que se viu em guerra. Ora, ha circumstancias anormaes, em que ouro assume seu caracter primitivo, assim como a defesa armada substitue, em casos raros, a organizada pela sociedade. Já expliquei, no artigo que escrevi para o "Jornal do Commercio", e a que acima me referi, ter sido perfeitamente justificavel a attitude de Murtinho, queimando papel moeda, e querendo e mesmo tentando a conversão de nosso meio circulante em moeda metallica: tinha necessidade de capitaes extrangeiros, e 
os capitalistas extrangeiros só se julgavam seguros contra o excesso de papel moeda, si o Brasil se obrigasse a manter-se na moeda metallica, que é a prova provała da existencia effectiva de riquezas poupadas ao consumo. A não ser nestes casos excepcionalissimos, e num delles se acha hoje a Argentina, em suas combinações mercantis com a America do Norte, não devemos nos impressionar com a falta de metaes. Possuir muito ouro não significa ser um paiz rico. A Hespanha, repetem todos os mestres de Economia Politica, esteve em verdadeira miseria, ao tempo em que se viu abarrotada pelo ouro da America. Caso analogo é o das republicas do Pacifico, as quaes empobreceram com a exportação do guano, que as enchia de ouro. 0 proprio Brasil, com a industria do café e da borracha, muito semelhantes á da extracção do ouro, tem soffrido muito. Nas regiões do café, impossivel é o estabelecimento de qualquer outra cultura, pois ninguem irá crear abelhas, fabricar queijos, cuidar de sericultura, salvo em condições excepciọnalissimais, si tem a industria muito mais facil e muito mais rendosa da cultura do café. Dahi a perda até dos conhecimentos technicos tradicionaes dessas industrias abandonadas, facto que se revela pela ignorancia de nossos lavradores, tẩo insistentemente denunciada pelos jornaes. Não é só, pois, ter ouro, nem ter grande somma de alguns productos que facilmente dão ouro, muito ouro, que significa que um paiz é rico. Não basta tambem achar-se em crédito nas relações mercantis internacionaes. Daniel Bellet, no artigo a que acabei de me referir, estudando a riqueza da Allemanha, procura definir o que é um paiz realmente rico, indaga o que constitue a "prosperidade nacional", e em que consistem as "forças economicas", de que falla toda a gente, e de que poucas pessoas têm uma clara noção. Parece inclinar-se á opinião de quc é o paiz que tem maior quantidade de capitaes empregados em produzir, que maior porção de seus productos consegue reservar, destinando-os a serem factores de 
nova producção, que tem mais perfeita distribuição dos productos, que têm uma circulação mais facil e rapida, onde o consumo é proporcionado á producção... E' assumpto que muito occupa a attenção de Hellferrich, director do "Deutsch Bank", a repartição ou distribuição dos productos pelas differentes categorias da população. 0 "Dresdner Bank" ligou grande importancia ás forças economicas, ou' aos factores da producção. Tudo ainda se complica pela difficuldade, sinão impossibilidade da fixação do "standard of life", com que se deve determinar o consumo. Wagner, em sua monumental obra sobre a Economia Politica, no L. 3 C. 5, ao tratar dos caracteristicos do "bem estar nacional", dá-nos, pela mais rapida e desattenta leitura, desde logo a impressão de quão absurdo é pretender que seja o bem estar determinado por ter o paiz muito ouro. Começa Wagner o estudo por uma bibliographia, que nos fornece uma enorme bibliotheca sobre a materia. Passa depois a enumerar e explicar os caracteristicos desse bem estar. Não se póde, em artigo destinado a um jornal diario, reproduzir, nem mesmo resumidamente, o que diz o mestre. Direi comtudo que se occupa, nas tres ultimas paginas, o grande economista com a significação do estado internacional do credito, com a balança dos pagamentos, e emfim com o total, a qualidade e a quantidade dos valores em moeda metallica, na fiduciaria e em titulos de credito. Como se vê, o assumpto é muitissimo difficil, e constitue um dos mais ardúos problemas da sciencia, como ficou dito, determinar, fixar em que consiste a verdadeira riqueza de um paiz. O que é facil se estabelecer, como tambem já affirmei, é que não basta ter ouro para poder ser considerado rico um povo. Realmente é desejavel que um povo feche sua "bralança de contas" em credito, mas isto não deve ser a unica preoccupação de um Estado. De que serve estar em credito si não se attender ás multiplas necessidades do povo, necessidades que não sendo satisfeitas o tornarão infeliz? A 
riqueza é meio e não fim. Fallo em geral, sem me referir a este ou a outro qualquer povo. Quero, porém, agora, occupar-me do nosso Brasil, que, por ser paiz novo, se acha, a este respeito, em condições especiaes.

7) Sabe qualquer pessoa medianamente versada em transacções bancarias, que hoje não se paga divida externa com ouro, sinão excepcionalissimamente. Ainda quando fica um paiz devedor na balança de contas, o pagamento é feito por meio de cambiaes de particulares, ou mesmo do governo, como no caso de emprestimo externo. Isto posto, supponhamos que o nosso paiz importe mais do que exportou. Supponhamos que tem, entretanto, empresas altamente productivas. Admittamos ainda que inspire a seus credores extrangeiros uma grande confiança. Dadas estas circumstancias, teremos nós de remetter ouro ou seu equivalente ao extrangeiro? Ver-nos-emos obrigados a entregar ao extrangeiro os capitaes que aqui temos applicados em produzir? Evidentemente, não. Si nossas condições de producção forem prosperas, nenhum interesse têm os capitalistas extrangeiros em exigir seus capitaes que aqui sc acham em boas empresas. E', pois, para a boa applicação de capitaes, embora com remuneração em tempo alogum tanto remoto, que deve se voltar nossa attenção.

Como não escrevo só para os versados nos segredos da summamente difficil sciencia a que dediquei particularmente minha actividade, darei uma explicação, que será facilmente comprehendida pelos menos conhecedores das leis economicas.

Si um fazendeiro antigo começa a fechar seus balanços em debito, é evidente que seus credores tratarão de liquidar com elle suas contas, e a liquidação poderá ser ruinosa, porque será precipitada. Cousa diversa succede ao agricultor que está abrindo fazenda: é natural que encha a praça com suas letras, é de esperar que feche em debito seus balanços, e nada disto aconselha seus credores a fazerem com elle liquidações precipitadas e ruinosas. 
Precisamente é o caso de um paiz novo, é o caso do Brasil. Não temos necessidade de liquidações, de sacrificios, de humilhações, porque, felizmente, é prospero nosso paiz. Ainda agora tivemos, para a prova disto, a exposição industrial, que patenteou nosso progresso aos olhos de todos que a visitaram. Foi uma pequena exposição, mas de elevadissimo valor, porque provou, com a eloquencia dos factos, que o brasileiro não é este preguiçoso, descripto e ridicularizado pelos que fallam de nosso povo, sem o conhecer. Repito, e não me cançarei de repetir: a Europa tem uma organização economica formada pela acção de muitos seculos de trabalho; a America do Norte e a Argentina, dotadas de clima temperado, egual ao da Europa, puderam acceitar "a civilização dativa", que lhes veiu do velho continente, sem nenhum trabalho, sem nenhum esforço de adaptação. Differente é a situação de nossa patria, que teve de crear novos processos technicos. Mas passarei aos problemas economicos, e para começar direi duas palavras sobre a intensificação da producção, assumpto de que todos se occupam neste momento, e de que nunca se dirá demais.

8) Antes de ser iniciada a guerra, era a preoccupação de todos o repouso, a diminuição de horas de trabalho. Alguns economistas, e dentre elles destacarei Leroy Beaulieu, faziam sentir os perigos desse rumo que tomava a producção. Ninguem quer ver o trabalhador esgottado pelo serviço. Ninguem póde accéitar por boa a organização do serviço descripta por Fraser, como sendo a adoptada pela America do Norte, onde raramente os operarios chegam aos trinta annos, diz o illustre escriptor inglês. Ninguem contesta que tenha sido uma grande e valiosa conquista o dia de 8 horas. 0 que, porém, se reconheceu, após a guerra começada, foi que houvera excesso na lucta contra o trabalho demasiado, como confessa o proprio Gide, insuspeito, por ser homem summamente caridoso e inclinado á defesa dos interesses do trabalhador. Vemos 
pois que não é possivel chegar ao idéal afagado pelos socialistas extremados, quando aindà reinava paz na Europa. Achamo-nos na contingencia de exigir dos homens o duro sacrificio de maior trabalho. $\mathrm{Na}$ solução do problema, porém, têm sido deixadas na penumbra, ou antes, em completo esquecimento, duas circumstancias que julgo capitaes. Não se tem dito quão importante é o melhoramento dos processos technicos para a intensificação da producção, quanto vale tambem a educação technica para este fim. E', creio, este o principal escolho encontrado pelo nosso povo: o brasileiro não é preguiçoso, como se diz, mas ignorante. Como se ha de arriscar a produzir, quando sabe que seus productos serão supplantados no mercado por outros de superior qualidade? A educação technica é, pois, um dos elementos para a prompta solução desse premente problema de augmento de producção. A outra circumstancia é a perda de tempo.

Nós perdemos tempo em esperarar á porta dos bancos pelo pagamento de um cheque, não ha pontualidade em nenhuma reunião, ficamos ás portas das repartições publicas, durante horas e dias, "até mesmo para pagamento de impostos". Imaginemos quantos milhares de individuos são conservados, por esta fórma, na ociosidade. De que serve que os juizes, quando fazem grande trabalho, condemnem meia duzia de vadios, si diariamente ha homens' cujo serviço significa muitos milhares de contos, perdidos por uma inercia forçada, em consequencia de não attendermos ao valor que tem o tempo? Dizem os ingleses que "tempo é dinheiro", mas, pelo que nos refere Spencer da vida norte-americana, foi este povo que tomou á letra o proverbio ingles. As cousas lá são arranjadas de modo a não serem desperdiçadas as forças productoras do paiz. Para a reforma da educação technica, e para o modo de evitar a perda das forças das pessoas que desejam trabalhar, produzir, chamo toda a attenção dos com- 
petentes: não é problema economico, mas juridico e administrativo.

9) Ainda em relação ao augmento da producção, devo fazer notar que ao Estado cumpre animar o desenvolvimento de certas industrias que.não remuneram o particular, mas que são uteis para a communhão. Si é difficil a producção do trigo, a criação de animaes para a nossa cavallaria, a producção mesmo dos cereaes, 'que em tempos normaes, em tempo de paz, não dãơ o lucro do café, cumpre ao Estado considerar que a monocultura nos póde crear difficuldades em caso de guerra, mesmo extrangeira, como ficou provado na aetual conflagração. Sirva-nos de exemplo a Inglaterra, que, com ser muito bem dirigida, commetteu o erro de desenvolver sua industria manufactora com as materias primas vindas de fóra, descuidando-se da producção de generos alimenticios: Dahi lhe resultaram serios embaraços na actual guerra.

10) Mas não basta o augmento da producção para se considerar resolvido o problema economico da riqueza. De que serve produzir-se muito, si uma classe, abusando do mau systema de distribuição dos productos, enriquece, ao passo que outra fica em negra e extrema miseria, creando-se mesmo dest'arte, no paiz, o pauperismo com todos os seus horrores? Como tambem desenvolver a producção sem uma boa circulação monetaria, pois é sabido que uma das mais importantes funcções da moeda é justamente approximar o trabalho do capital? Todos conhecem os milagres do credito, que fazem que alguns economistas affirmem que elle é capital, quando outros, entre os quaes Gide, entendem que elle não é "agente de producção", mas "modo especial de producção"; tornando possivel que uma pessoa use de capital de outra. Não é ainda sufficiente organizar a producção e a distribuição ou repartição da riqueza. E' indispensavel que se facilite sua circulação, já por uma boa organização de nosso meio 
imperfeitos ainda em nossa Patria, e que, quando melhorados, animarão os productores. E' sabido que a procirculante, aproveitando-se o credito dos particulares, com já particularmente cuidando dos meios de transporte, tão estalbelecimentos bancarios, já auxiliando a commercio, ducção, ainda nas terras mais ferteis, deperece, quando são insufficientes os meios de transporte, e deste phenomeno nos dão noticia illustres escriptores, referindo-se á terra uberrima da região do Caucaso e á Calabria. Emfim, na reforma economica a que nos devemos applicar com aferro, não póde ficar esquecido o que ha de difficil na regularização do consumo. As classes poḅres devem merecer nossa attenção, sob pena de vermos uma parte avultada de nossa população sacrificada pela mais feliz, e assistirmos á reproducção das scenas que, em meio do anno passado, ensanguentaram as ruas desta capital. Comparemos, nesse ponto, nossa situação com a dos povos que hoje regulam, forçados pela guerra, o consumo de artigos de primeira necessidade com um rigor, como diz Gide, que só não é ridiculo por ser filho da necessidade, e portanto, gerar em nós a admiração pelo modo resignado por que todos os cidadãos se submettem a essa regulamentação. Em uma notavel prelecção, das com que o grande Gide empolga a attenção de seus ouvintes, mostrou o mestre os varios processos de regulamentação do consumo. $\mathrm{Na}$ Revista de Economia Politica acham-se muitos desses regulamentos, ultimamente expedidos em França e na Allemanha. Em plena paz, estamos felizmente longe de pensar em applicar taes rigorosas medidas á nossa Patria. Da leitura, porém, desses trabalhos, infere-se que algumas providencias analogas, verdadeiras attenuações das do periodo de guerra, poderiam ser estabelecidas, mesmo para o tempo de paz: é até o desejo que transparece na prelecção de Gide, a que acabo de me referir. Direi ainda que, si a guerra forçou allemães, ingleses e franceses a submetter-se a um regimen rigoroso no, consumo, é de esperar 
que a simples noticia que tem nosso povo do que se passa hoje no velho continente, faça que elle, de bom grado, se sujeite aos conselhos dados pela sciencia, quando transformados em preceitos legaes.

Dir-se-á que estou na 'região da utopia. Mas é aos homens da sciencia que toca andar a buscar os idéaes, a pedir muito para que os homens da lei façam um pouco. 0 economista diz tudo quanto se deve realizar para o bem estar social, aponta as medidas, as providencias que seriam proveitosas, e o politico vê o que póde desde logo fazer e tornar effectivo.

11) Quero, porém, que fique bem accentuado que estou longe de pensar que nos achamos em situação critica, em condições de nos apavorarmos ácerca de nosso futuro. No momento actual, idurante a guerra, temos para nos acudir a exportação de cereaes, oleaginosos, carnes, etc. Pois bem! Quando, para felicidade da civilização, cessar o troar dos canhóes, será restabelecido o nosso commercio de café e de borracha, com que poderemos ir nos mantendo, até que consigamos a regeneração economica, de que vai o nosso governo cuidando, a reorganização de nosso systema economico-financeiro. Os problemas da intensificação da producção pertencem, em grande numero, antes á technologia do que á Economia Politica, pois o desenvolvimento da agricultura, o aperfeiçoamento das industrias manufactoras sahem, quasi, por completo, do quadro dos assumptos pertencentes á Economia Social.

Entrètanto, a fórma de economizar o tempo, o modo de desenvolver a educação technica, a introducção de mestres em artes uteis, são assumptos que tocam ao Direito, á administração, á Politica e á Economia Social.

Braz de Sousa Arruda, 